\title{
Empirical Observations on the Tracking Errors and the Risk-Adjusted Returns of REIT-Based Exchange Traded Funds
}

\author{
Subhashis Nandy ${ }^{1}$ \\ ${ }^{1}$ Faculty, School of Advanced Studies, University of Phoenix, Arizona, USA \\ Correspondence: Subhashis Nandy, Faculty, School of Advanced Studies, University of Phoenix, Arizona, USA. \\ E-mail: subasnandy@email.phoenix.edu
}

Received: June 20, 2016

doi:10.5539/ijbm.v11n9p63

\author{
Accepted: July 8, 2016 \\ Online Published: August 10, 2016 \\ URL: http://dx.doi.org/10.5539/ijbm.v11n9p63
}

\begin{abstract}
In the last few years, investments in exchange traded funds (ETFs) have gained significant popularity among the financial investors. Financial investors have also shown enormous interests in investments in REITs (Real Estate Investment Trusts). The researcher has determined the tracking errors of REIT based ETFs from the corresponding REIT indexes. The null hypotheses that there are no correlations between the risk adjusted returns of REIT based ETFs and the risk-adjusted returns of the corresponding index have been tested at 0.05 levels of significances. The period used in this study is from April 2010 to March 2016. The results indicate that the mean tracking errors of REIT based ETFs are very small. The findings also indicate that the null hypotheses that there are no correlations between the risk-adjusted returns of REIT based ETFs and the risk adjusted returns of the corresponding index can be rejected at 0.05 levels of significance.
\end{abstract}

Keywords: US Wilshire REIT Index, FTSE NAREIT US Real Estate 50 index, Claymore US Wilshire REIT index ETF, iShares Real Estate 50 ETF, tracking errors, risk-adjusted returns

\section{Introduction}

\subsection{Introduce the Problem}

In the last few years, Exchange Traded Funds (ETFs) have gained preferences among investors as investment options (Bas et al. 2015, and Charupat \& Miu, 2013). ETFs have certain advantages, such as, low expense ratios, intraday trading, tax efficiency and transparency in costs (Charupat \& Miu, 2013). Another development in the financial markets in the last several years has been the persistent existence of low-interest rates. This situation has presumably led to the popularity of Real Estate Investment Trusts (REITs) among investors as high-yield financial instruments (Goebl, Harrison, Mercer \& Whitby, 2013). Lee, Chiu, Lee, Chiang, \& Slawason (2010), and Ivanov (2013) stated that REITs are mandated by the current tax laws to distribute at least $90 \%$ of all income to their investors as dividends. REIT index ETFs are designed to track well known real estate industry indexes, such as, the US Wilshire REIT index or, FTSE NAREIT US Real Estate 50 index. The problem that exists today is that the financial investors do not have accurate information available on the tracking errors of REIT index-based ETFs. The tracking errors in REIT index-based ETFs can cause the financial returns of these funds to deviate significantly from the corresponding financial returns of the underlying indexes.

\subsection{Explore the Importance of the Problem}

The tracking errors designate the differences in the mean returns of index ETFs from that of the underlying indexes (Purohit Chowdhry, \& Tyagi, 2014). Rompotis (2011) documented that the tracking errors of index ETFs persisted at short-term level. This author used data from a sample of 50 ishares ETFs during the period 2002 to 2007. However, this author's analysis excluded any REIT index ETF. Bello (2012) indicated that small-cap index ETFs had larger tracking errors than small-cap index mutual funds. Drenovack, Urosevic, and Jelic (2014) showed that the existence of significant tracking errors in European bond ETFs led to underperformance of these ETFs relative to their benchmarks. It is important to note that although the tracking errors of several equity and bond index based ETFs had been published in the literature, no significant work exists in the literature on the tracking errors of REIT index based ETFs.

\subsection{Describe the Relevant Scholarship}

In an early work, Kostovesky (2003) showed that the main difference in performances of index mutual funds and 
index ETFs are in the management fees, shareholder transaction fees, and taxation efficiencies. According to Kostovetsky (2003), tracking errors of these funds were difficult to model because there was not a true benchmark to follow.

Cremers and Petajisto (2009) documented that the funds with portfolio holdings that were different from the tracked indexes would outperform the underlying indexes. These funds would also have persistence performances over time, but higher tracking errors.

Rompotis (2011) documented that the majority of 50 ishares ETFs selected for his study exceeded the financial returns of the underlying indexes at the annual and aggregate levels. Further, this author showed that the tracking errors of the ETFs also persisted at the short-term level. Chu (2011) showed that Hong Kong based ETFs had high tracking error as compared to ETFS traded in USA and Australia. Chu (2011) determined that there was positive correlation between management expense ratio of an ETF and its tracking error.

Bello (2012) showed that both small-cap index ETFs and index mutual funds underperformed the underlying Russell 2000 index. However, this author showed that the index mutual funds outperformed the corresponding index ETFs during the sampling period from January 2001 to March 2012. Further, Bello (2012) showed that the tracking errors of these ETFs and mutual funds from the corresponding Russell 2000 index were very high.

Tang and Xu (2013) examined the tracking error of an US-listed ETF that tracked a particular China-based Real Estate index. These authors determined that significant short-term tracking errors existed for the particular US-listed ETF. However, their analysis also showed that significant return deviations for the longer periods were not generated. Drenovack et al. (2014) showed the existence of significant tracking errors in European bond ETFs. These ETFs produced lower financial returns compared to their benchmark bond indexes.

Purohit, Choudhary \&Tyagi (2014) showed that India-based ETFs had significant tracking errors from the underlying indexes. According to these authors, some of the factors that could lead to the tracking errors were: discounts/premiums on Net Asset Values, portfolio optimization and portfolio diversification constraints, cash drag/accumulations, index changes, capital gain distributions, securities lending, currency hedging and maintaining constant leverage (Purohit, Choudhary \& Tyagi, 2014).

Leung and Ward (2015) focused on the tracking errors of leveraged exchange traded funds in gold. These authors showed that these ETFs had tracking errors with leveraged position in gold over long time periods. Maverick (2016) stated that tracking error was the amount by which a fund's financial return, as indicated by its net asset value (NAV), varied from the financial return of the underlying index.

In a recently published paper, Osterhoff and Kaserer (2016) showed that the daily tracking errors of German ETFs depended significantly on the liquidity of the underlying stocks. These authors speculated that the reason for the existence of the daily tracking errors might be due to the imperfect replication of the index weights in the ETFs.

\subsection{State the Hypothesis}

The first objective of this research work is to determine the tracking error of Claymore US Wilshire REIT index ETF (ticker symbol: WREI), which is supposed to track the US Wilshire REIT index. The period considered for this study is from April 2010 through March 2016. The period selected for this study was from April 2010 through March 2016 - because the trading for WREI started in the stock exchange from March 9, 2010. The second objective is to determine the tracking error of iShares Real Estate 50 ETF (ticker symbol: FTY), which is supposed to track the FTSE NAREIT US Real Estate 50 index. The period considered for this study is also from April 2010 through March 2016. The third objective is to establish a linear relationship between the risk-adjusted monthly return of Claymore US Wilshire REIT index ETF and the risk-adjusted monthly return of the underlying US Wilshire REIT index from April 2010 through March 2016. The risk-adjusted monthly return or, excess return is calculated by subtracting the monthly risk-free returns of the Treasury 91-day bill from the monthly returns of the ETF and the underlying index. The final objective is to establish a linear relationship between the risk-adjusted monthly return of iShares Real Estate $50 \mathrm{ETF}$ and the risk-adjusted monthly return of the underlying FTSE NAREIT US Real Estate 50 index from April 2010 through March 2016.

The hypotheses tested in this study are:

$\mathrm{H}_{\mathrm{o}}$ (Null): There is no linear correlation between the risk-adjusted return of REIT index ETF and the risk-adjusted return of the underlying REIT index.

$\mathrm{H}_{\mathrm{a}}$. (Alternative): There is a linear correlation between the risk-adjusted return of REIT index ETF and the risk-adjusted return of the underlying REIT index. 
The monthly yield data for the 91-day Treasury bill were obtained from the website of St Louis Federal Reserve Bank - research.stlouisfed.org.

The monthly data for the Guggenheim US Wilshire REIT index ETF (ticker symbol: WREI) were obtained from www.bloomberg.com/quote/WREI:US. WREI tracks the US Wilshire REIT index. The monthly data for the US Wilshire REIT index were obtained from the website of St Louis Federal Reserve Bank - research.stlouisfed.org.

The monthly data for iShares Real Estate 50 ETF (ticker symbol: FTY) were obtained from http://www.bloomberg.com/quote/FTY:US. FTY tracks the FTSE NAREIT US Real Estate 50 index. The monthly data for the FTSE NAREIT US Real Estate 50 index were obtained from the website-www.reit.com.

\section{Method}

A linear regression (OLS-Ordinary Least Squares) model is used to determine correlation between the risk-adjusted performance of REIT ETF and the risk-adjusted performance of the underlying REIT:

$$
R_{i t}=\alpha_{i}+\beta_{i} R_{m t}+\varepsilon_{i j}
$$

In the above expression, $\mathrm{R}_{\mathrm{it}}$ is the excess return (or, risk-adjusted return) of the real estate investment trust index ETF i (either Wilshire REIT index ETF, or FTSE NAREIT US index ETF) in month $t$. It is equivalent to the ETF i's return in excess of the corresponding monthly yield on 91-day-treasury bills. $\mathrm{R}_{\mathrm{mt}}$ is the excess return (or, risk-adjusted return) of the corresponding real estate investment trust index (either Wilshire REIT index, or FTSE NAREIT US index), and $\varepsilon_{\mathrm{ij}}$ is the residual return. ETF i's risk-adjusted performance is measured by Jensen's alpha, $\alpha_{\mathrm{i}}$ (Bello, 2012). $\alpha_{\mathrm{i}}$ is a measure of the excess return of the real estate investment trust index ETF $i$, when the excess return of the corresponding real estate investment trust index is zero. $\beta_{i}$ measures the change in $\mathrm{R}_{\mathrm{it}}$ (risk-adjusted return of the real estate investment trust index ETF i) for an unit change in $\mathrm{R}_{\mathrm{mt}}$ (risk-adjusted return of the corresponding real estate investment trust index). Reily and Norton (2006) stated that the Sharpe information Ratio, $S_{p}$, is a general measure of portfolio performance. According to Bello (2012), Sharpe Information ratio values adjust for total risk. The Sharpe information ratio is defined as:

$$
S_{p}=D_{a v} / \sigma_{D}
$$

$\mathrm{D}_{\mathrm{av}}$ is the arithmetic average of the monthly differential returns between index ETF and the corresponding index (that is, $\mathrm{D}=\mathrm{R}_{\mathrm{it}}-\mathrm{R}_{\mathrm{mt}}$ ). Thus,

$$
D_{a v}=(1 / n) \sum D_{i},
$$

$\sigma_{\mathrm{D}}$ is the standard deviation of the differential returns, and $\mathrm{n}$ is the number of monthly return periods. The tracking error (TE) of the ETF from the underlying index is given as follows:

$$
T E=\sigma_{D}(12)^{(0.5)}
$$

The number of periods of financial return (n) in a given year is 12 .

\subsection{Sample Selection}

For our research the researcher has utilized the monthly closing prices of the Guggenheim US Wilshire REIT index ETF (ticker symbol: WREI), and the corresponding US Wilshire REIT index from April 2010 to March 2016. The period selected for this study was from April 2010 through March 2016-because the trading for WREI started in the stock exchange from March 9, 2010. The monthly closing prices of iShares Real Estate 50 ETF, and the corresponding FTSE NAREIT US Real Estate 50 index from April 2010 to March 2016 (a total time period of 72 months) were also utilized in this study.

\section{Results}

In Table 1 the descriptive statistics analysis of the monthly excess return data of the two REIT ETFs and the corresponding REIT Indexes are shown. 
Table 1. Descriptive statistics of monthly excess returns of ETFs and corresponding indexes

\begin{tabular}{|c|c|c|c|c|c|c|}
\hline \multicolumn{7}{|l|}{ Monthly Excess Return } \\
\hline & & & Standard & & & \\
\hline & Mean & Median & Deviation & Minimum & Maximum & Skew \\
\hline \multicolumn{7}{|l|}{ Claymore US Wilshire REIT ETF } \\
\hline$(\mathrm{WREI})$ & 0.0107 & 0.0178 & 0.0456 & -0.0978 & 0.1467 & -0.006 \\
\hline US Wilshire REIT Index & 0.0127 & 0.011 & 0.0537 & -0.1402 & 0.1607 & 0.003 \\
\hline iShares Real Estate 50 ETF (FTY) & 0.0098 & 0.0092 & 0.0431 & -0.0897 & 0.1171 & -0.099 \\
\hline \multicolumn{7}{|l|}{ FTSE NAREIT US Real Estate 50} \\
\hline Index & 0.0103 & 0.0092 & 0.043 & -0.1074 & 0.1348 & -0.075 \\
\hline
\end{tabular}

The comparison of measures of the financial performances of the two REIT index ETFs is listed in Table 2. The results from the null hypothesis tests of no correlation between the independent variable and the dependent variable at 0.05 levels of significance are shown in Table 3 .

Table 2. Comparison of measures of the financial performances for FTY and WREI ETFs

\begin{tabular}{llllllll}
\hline \multicolumn{7}{c}{$\begin{array}{l}\text { Measures Of Performance for FTY and WREI } \\
\text { April 2010 to March 2016 }\end{array}$} \\
\hline \multicolumn{7}{c}{ FTY(ETF) } \\
& $\mathrm{n}$ & Mean & Minimum & Maximum & Mean & Minimum & Maximum \\
\hline Dav & 12 & 0.0004 & 0.0002 & 0.0009 & 0.0009 & -0.0078 & 0.0183 \\
$\sigma \mathrm{D}$ & 12 & 0.0006 & 0.0025 & 0.0142 & 0.0699 & 0.0494 & 0.0915 \\
$\mathrm{Sp}$ & 12 & 0.0883 & 0.0223 & 0.1708 & 0.0025 & -0.0912 & 0.2113 \\
$\mathrm{TE}$ & 12 & 0.0202 & 0.0087 & 0.0493 & 0.2407 & 0.1711 & 0.3171 \\
$\beta$ & 12 & 1.0002 & 0.9917 & 1.021 & 0.9542 & 0.7293 & 1.0655 \\
$\alpha$ & 12 & -0.0005 & -0.0012 & -0.0001 & 0.0006 & -0.0002 & 0.0007 \\
\hline
\end{tabular}

Table 3. Results from null hypothesis tests of no correlation at 0.05 levels of significance

\begin{tabular}{llllll}
\hline Number & Time Period & Dependent Variable & Independent Variable & p-value & Decision \\
\hline 1 & $04 / 10-03 / 11$ & Monthly Return of FTY & Monthly Return of Index & 0 & Reject Ho \\
2 & $04 / 11-03 / 12$ & Monthly Return of FTY & Monthly Return of Index & 0 & Reject Ho \\
3 & $04 / 12-03 / 13$ & Monthly Return of FTY & Monthly Return of Index & 0 & Reject Ho \\
4 & $04 / 13-03 / 14$ & Monthly Return of FTY & Monthly Return of Index & 0 & Reject Ho \\
5 & $04 / 13-03 / 15$ & Monthly Return of FTY & Monthly Return of Index & 0 & Reject Ho \\
6 & $04 / 15-03 / 16$ & Monthly Return of FTY & Monthly Return of Index & 0 & Reject Ho \\
7 & $04 / 10-03 / 11$ & Monthly Return of WREI & Monthly Return of Index & 0 & Reject Ho \\
8 & $04 / 11-03 / 12$ & Monthly Return of WREI & Monthly Return of Index & 0 & Reject Ho \\
9 & $04 / 12-03 / 13$ & Monthly Return of WREI & Monthly Return of Index & 0 & Reject Ho \\
10 & $04 / 13-03 / 14$ & Monthly Return of WREI & Monthly Return of Index & 0 & Reject Ho \\
11 & $04 / 13-03 / 15$ & Monthly Return of WREI & Monthly Return of Index & 0 & Reject Ho \\
12 & $04 / 15-03 / 16$ & Monthly Return of WREI & Monthly Return of Index & 0 & Reject Ho \\
\hline
\end{tabular}

\section{Discussion}

The results from Table 1 indicate that mean values of the monthly excess returns of the REIT ETFs and the corresponding indexes are quite similar. The skew values of the indexes and the ETFs are slightly negative but very close to zero-suggesting symmetrical characteristics in the distributions of the monthly excess returns. The skew value for US Wilshire REIT index is slightly positive, but very close to zero.

From the results shown in Table 2, it is evident the average difference in the mean return of the WREI ETF from its corresponding index (Dav) is greater than that of the FTY ETF from its corresponding index over the study period. It is also observed that mean the tracking error (TE) of the WREI ETF from its corresponding index is greater than the tracking error of the FTY ETF from its corresponding index. The mean tracking error values of both of these real estate investment trust ETFs are comparatively small. These findings are slightly different that 
of Bello (2012), who determined that the Russell 2000 index based ETFs and mutual funds showed very large tracking errors from the corresponding index.

The data in Table 2 show that the mean Sharpe Information ratio (Sp) value of FTY ETF is greater than that of WREI ETF over the study period. However, both of the mean Sharpe Information ratio values are positive, which indicates that both of the ETFs overperformed the corresponding indexes.

The mean value of the slope $(\beta)$ of the linear regression between the excess average return of FTY ETF (dependent variable) with the excess average return of the corresponding index (independent variable) is slightly greater than 1 . This suggests that the mean excess return of WREI very slightly over performed that of the corresponding index over the study period.

The mean value of the slope $(\beta)$ of the linear regression between the excess average return of WREI ETF (dependent variable) with the excess average return of the corresponding index (independent variable) is slightly lower than 1. This suggests that the mean excess return of FTY very slightly underperformed that of the index over the study period.

The data in Table 2 show that mean value of intercept $(\alpha)$ of the linear regression between excess average return of FTY ETF and the excess average return of the corresponding index is very slightly lower than zero. The mean value of the intercept $(\alpha)$ of the linear regression between the excess average return of WREI ETF and the excess average return of the corresponding index is very slightly greater than zero. This means that the excess returns of both of these ETFs are close to zero, when the excess returns of the corresponding indexes are also zero.

The data from Table 3 suggest that the null hypotheses that there are no correlations between the risk-adjusted returns of FTY ETF and the returns of the corresponding index for the six annual periods can be rejected at a 0.05 level of significance. It is also observed that the null hypotheses that there are no correlations between the risk=adjusted returns of WREI ETF and the returns of the corresponding index for the six annual periods can be rejected at a 0.05 level of significance.

It can be concluded from the current work that the tracking errors of the REIT index-based ETFs from the corresponding indexes are quite small. Further, the small mean values of Jensen's alpha and Sharpe Information ratios of these ETFs suggest that the investors in these ETFs are not exposed to undue systematic and total risks, as compared to investing in the corresponding indexes. These findings are important to the investors, because they can make well informed decisions to invest in two different REIT index-based ETFs. These findings are different from that of Bello (2012), who showed that the tracking errors of Russell 2000 index-based ETFs and index-based mutual funds were very high.

In this paper, the researcher has determined the tracking errors of the REIT index-based ETFs. The researcher has tested the following null hypothesis at a 0.05 level of significance: no correlation exists between the excess returns of REIT ETFs and the excess returns of the corresponding REIT indexes. The results of this hypothesis test indicate that the null hypothesis that no correlation exists between the two excess returns can be rejected. Some of the limitations of this study could be: (1) the researcher has utilized financial data on FTY, WREI, US Wilshire REIT index and FTSE NAREIT US Real Estate 50 index from April 2010 to March 2016; results may differ when the data will be analyzed for different periods; (2) the researcher has determined tracking errors of REIT index based ETFs only, the tracking errors of other index based ETFs from the corresponding indexes may be different.

\section{References}

Bas, N. K., \& Sarioglu, S. E. (2015). Tracking Ability and Pricing Efficiency of Exchange Traded Funds: Evidence from Borsa Istanbul. Business and Economics Research Journal, 6(1), 19-33.

Bello, Z. (2012). The Investment Performance and Tracking Errors of Small Cap ETFs. Global Journal of Finance and Banking Issues, 6(6), 12-20.

Charupat, N., \& Miu, P. (2013). Recent developments in exchange-traded fund literature: Pricing efficiency, tracking ability, and effects on underlying securities. Managerial Finance, 30, 427-443. http://dx.doi.org/10.1108/03074351311313816.

Chu, P. K. K. (2011). Study on the Tracking Errors and Their Determinants: Evidence from Hong Kong Exchange Traded Funds. Applied Financial Economics, 21(5), 309-315. http://dx.doi.org/10.1080/09603107.2010.530215

Cremers, K. J. M., \& Petajisto, A. (2009). How Active Is Your Fund Manager? A New Measure That Predicts Performance. The Review of Financial Studies, 22(9), 3329-3365. http://dx.doi.org/10.1093/rfs/hhp057 
Drenovack, M., Urosevic, B., \& Jelic, R. (2014). European Bond ETFs: Tracking Errors and Sovereign Debt $\begin{array}{llll}\text { Crisis. } & \text { European } & \text { Financial }\end{array}$ http://dx.doi.org/10.1111/j.1468-036X.2012.00649.x

Goebl, P. R., Harrison, D. M., Mercer, J. M., \& Whitby, R. J. (2013). REIT Momentum and Characteristic-Related REIT Returns. Journal of Real Estate Finance and Economics, 47(3), 564-581. http://dx.doi.org/10.1007/s11146-012-9371-2.

Ivanov, S. I. (2013). Analysis of REIT and REIT ETFs Cointegration during the Flash Crash. Journal of Accounting and Finance, 13(4), 74-81.

Kostovetsky, L. (2003). Index Mutual Funds and Exchange-Traded Funds. A comparison of two methods of passive investment. The Journal of Portfolio Management, 29(4), 80-92. http://dx.doi.org/10.3905/jpm.2003.319897

Lee, M. T., Chiu, B. H., Lee, M. L., Chiang, K. C. H., \& Slawson, V. C. (2010). REIT excess dividend and information asymmetry: Evidence with taxable income. Journal of Property Investment and Finance, 20(3), 221-236. http://dx.doi.org/10.1108/14635781011048867

Leung, T., \& Ward, B. (2015). The golden target: Analyzing the tracking performance of leveraged gold ETFs. Studies in Economics and Finance, 32(3), 278-297. http://dx.doi.org/10.1108/SEF-01-2015-0009

Maverick, J. V. (2016). How can I calculate tracking error of an ETF or indexed mutual fund? Retrieved from http://www.investopedia.com/ask/answers/052815/how-can-i-calculate-tracking-error-etf-or-indexed-mutua 1-fund.asp

Osterhoff, F., \& Kaserer, C. (2016). Determinants of Tracking Errors in German ETFs-the role of market liquidity. Managerial Finance, 42(5), 417-437. http://dx.doi.org/10.1108/mf-04-2015-0105

Purohit, H., Choudhary, N., \& Tyagi, P. (2014). An evaluation of Tracking Errors on World Indices ETFs Traded in India. The IUP Journal of Applied Finance, 20(3), 41-52.

Reily, F. K., \& Norton, E. (2006). Investments (7th ed.). Toronto: Thompson South Western.

Rompotis, G. G. (2011). Predictable patters in ETFs' return and tracking error. Studies in Economics and Finance, 28(1), 14-35.

Tang, H., \& Xu, X. E. (2013). Tracking Performance of the United States-Listed China Real Estate ETF. The Chinese Economy, 46(5), 5-35. http://dx.doi.org/10.2753/CES1097-1475460501

\section{Copyrights}

Copyright for this article is retained by the author(s), with first publication rights granted to the journal.

This is an open-access article distributed under the terms and conditions of the Creative Commons Attribution license (http://creativecommons.org/licenses/by/4.0/). 